\title{
Electrodeposition of Nanocrystalline Fe-W Coatings from a Citrate Bath
}

\author{
S. S. Belevskii ${ }^{a}$, A. V. Gotelyak ${ }^{b}$, S. P. Yushchenko ${ }^{a}$, and A. I. Dikusar ${ }^{a, b}$, * \\ ${ }^{a}$ Institute of Applied Physics, Chisinau, MD-2028 Moldova \\ ${ }^{b}$ Shevchenko Pridnestrovie State University, Tiraspol, MD-3300 Moldova \\ *e-mail:dikusar@phys.asm.md \\ Received December 19, 2017; revised June 12, 2018; accepted July 2, 2018
}

\begin{abstract}
The electrode processes occurring during electrodeposition of nanocrystalline Fe-W alloy coatings from a citrate bath containing iron(II) sulfate and a tungstate ( $\mathrm{pH} 6.9 ; 80^{\circ} \mathrm{C}$, graphite anode) are studied by cyclic voltammetry. The current efficiency of alloy electrodeposition is up to $30 \%$, if the applied current density is confined to the range of $2-5 \mathrm{~A} / \mathrm{dm}^{2}$. The limitation on range of applied current densities is twofold: the lower limit is dictated by the diffusion-limited current density due to the reduction of the oxidized form of iron-citrate complex that forms at the bath preparation stage as a result of oxidation of Fe(II) species in a citrate solution; while the upper limit is imposed by the occurrence of side reactions such as the hydrogen evolution reaction and/or reduction of organic components of the bath. The use of an iron anode seems to be promising in this deposition process (the current efficiency of anodic dissolution of Fe in this bath is $93 \pm$ $2 \%$ ). The deposited coatings contain $\sim 25$ at $\%$ tungsten and their microhardness (which can be up to $900 \mathrm{kgF} / \mathrm{mm}^{2}$ ) depends on the volume current density. The studied system holds promise for application in mask-free localized electrodeposition.
\end{abstract}

Keywords: electrodeposition, Fe-W coatings, cyclic voltammetry, citrate bath, microhardness

DOI: $10.3103 / \mathrm{S} 1068375519020054$

\section{INTRODUCTION}

Thin films and quasi-one-dimensional structures made from alloys between iron-group metals and refractory metals such as $\mathrm{W}, \mathrm{Mo}$, and Re are highly promising materials in terms of their anticorrosive, reinforcing, catalytic, and magnetic properties. The electrodeposition of these alloys is at the cutting edge of electrochemical materials science research [1,2] because it is interesting from the perspective of both basic and applied science, e.g., for the development of methods for fabrication of wear and corrosion resistant coatings, as an alternative to chrome plating [17], catalysts for water electrolysis [1, 2, 8-10], and for data storage applications [2, 10-14]. Fundamental research on this topic is motivated by the fact that the mechanism of electrodeposition of such coatings has remained a subject of debate [1, 2, 15-19]. This being so, the electrodeposition of such alloys, commonly referred to as induced electrodeposition [1, 15, 16, 20], can still be considered anomalous [1].

Among these types of alloys, which are fabricated by the electrochemical route, $\mathrm{Fe}-\mathrm{W}$ coatings have an important place [14, 21-25]. The use of the bulk form of these alloys [1, 2, 21-25] and their quasi-onedimensional structures (e.g., nanowires, nanotubes, nanoribbons, and nanobelts [10]) in all the applica- tions mentioned above has been constantly expanding. New particular applications for these alloys and possibilities for their use in different technologies are being discovered. We highlight that ecologically benign baths (mainly neutral citrate and gluconate baths) can be used for electrodeposition of alloys between the iron group metals and refractory metals. In the electrodeposition of $\mathrm{Fe}-\mathrm{W}$ thin films and coatings, loss of stability and working capacity of the developed baths due to oxidation of bivalent iron species into trivalent ones by dissolved oxygen is a serious issue. Typically, to counteract this undesirable process, electrodeposition baths based on citrate-ammonia solutions containing bivalent iron have been used [26-28], but this approach has a negative impact on the ecological aspect of the technology. Attempts to develop ammonia-free electrodeposition baths or to considerably reduce the ammonia concentration can be found in literature $[7,23,24,29,30]$. In this regard, we highlight studies $[14,24,25]$ that have demonstrated the possibilities of an ecologically friendly citrate-glycolate bath based on trivalent iron: the bath exhibited superior performance and high deposition rates, and it enabled control over the composition, structure, and properties (mechanic and magnetic) of deposited alloys over a broad range. 
Table 1. Bath compositions (concentrations, mol/L)

\begin{tabular}{l|c|c|c|c}
\hline \multicolumn{1}{c|}{ Component } & I & II & III & IV \\
\hline $\mathrm{FeSO}_{4} \cdot 7 \mathrm{H}_{2} \mathrm{O}$ & - & 0.2 & 0.2 & 0.2 \\
Citric acid & 0.17 & 0.17 & - & 0.17 \\
Sodium citrate & 0.33 & 0.33 & - & 0.33 \\
$\mathrm{Na}_{2} \mathrm{WO}_{4} \cdot \mathrm{H}_{2} \mathrm{O}$ & - & - & - & 0.40 \\
$\mathrm{pH}$ & 6.8 & 6.9 & $\sim 1$ & 6.9 \\
\hline
\end{tabular}

The use of glycolic acid, however, makes this technology costly. For instance, the cost for glycolic acid required for preparing $100 \mathrm{~L}$ of the plating bath described in [24] amounts to $~ 500$ euro. Therefore, attempts to develop an ecologically benign bath without glycolic acid (e.g., based on citrate) for electrodeposition of $\mathrm{Fe}-\mathrm{W}$ coatings are certainly worth an effort. In this study, we aim at developing a citrate bath containing bivalent iron and not containing ammonia or its salts for the electrodeposition of $\mathrm{Fe}-\mathrm{W}$ coatings; we also investigate the properties of obtained coatings. This bath was shown to produce nanocrystalline coatings [14, 24, 25], which are different from crystalline coatings of electrolytic iron deposited from similar baths (citrate-based baths containing bi- and trivalent iron species). Put differently, the coatings from this bath acquire amorphous features due to the incorporation of a particular content of tungsten.

\section{EXPERIMENTAL}

Several compositions of the bath studied here are listed in Table 1. These are all based on a citrate bath (bath IV), which was used for the electrodeposition of $\mathrm{Fe}-\mathrm{W}$ coatings in [24]. Bath IV is a complete bath, in that it includes both a bivalent iron salt and sodium tungsten. The bath was prepared by dissolving first iron sulfate in a citrate buffer and then sodium tungstate; the $\mathrm{pH}$ of the resulting solution was 6.8-6.9. We emphasize that subsequently the electrodeposition and electrochemical investigation of redox processes by cyclic voltammetry $(\mathrm{CV})$ were carried out at this pH. Baths I-III are partial baths based on bath IV; however, in bath III, the $\mathrm{pH}$ was maintained at $\sim 1$ so the iron would precipitate at a neutral $\mathrm{pH}$ in the form of hydroxide. Majority of electrodeposition experiments and CV measurements were carried out at a temperature of $80^{\circ} \mathrm{C}$, since alloys between the iron group metals and tungsten are typically electroplated at elevated temperatures $\left(60-80^{\circ} \mathrm{C}\right)$ [2, 4-6, 23-26]. Nevertheless, some CV measurements in bath II were performed at room temperature $\left(25^{\circ} \mathrm{C}\right)$. In general, the electrodeposition experiments and CV measurements were carried out in the presence of dissolved oxygen from air, but the series of measurements reported here were done in argon-purged solutions to eliminate the influence of dissolved oxygen on the observed redox processes.
$\mathrm{CV}$ measurements were carried out in a three-electrode cell at a potential scan rate of $10 \mathrm{mV} / \mathrm{s}$. A platinum wire $\left(0.159 \mathrm{~cm}^{2}\right)$ and a saturated $\mathrm{Ag} / \mathrm{AgCl}$ electrode were used as the working and reference electrodes, respectively. The counter electrode was platinum as well. All CV curves were directed in the cathodic direction starting from an open circuit potential. The ranges of potential scanning and exact directions of potential sweeps will be shown below on $\mathrm{CV}$ profiles. Prior to measurements, the working electrode (platinum) was subjected to anodic-cathodic pretreatment (cleaning): the electrode was placed in $30 \%$ $\mathrm{HNO}_{3}$ in a two-electrode cell, along with another $\mathrm{Pt}$ electrode of a large surface area, connected as the cathode, and a potential difference of $1 \mathrm{~V}$ was applied; after a certain time, the voltage was reduced to $0.2 \mathrm{~V}$ and maintained until a peak on the cathodic current transient is passed. The values for rates of reactions, i.e., current densities, were calculated per geometric surface area of the platinum electrode. Electrochemical measurements were carried out on a PARSTAT 2273 potentiostat controlled by the manufacturer's software Power Suite, v. 2.58.

The iron concentration was determined spectrophotometrically in the presence of sulfosalicylic acid [31]. First, the total iron content was determined. For this, a solution of sulfosalicylic acid and an ammonia solution (dilution, $2: 3$ ) were added to an aliquot of the sample prepared under argon and using freshly boiled distilled water; the resulting mixture was left for $10 \mathrm{~min}$, and then its absorption at $430 \mathrm{~nm}$ was measured. The total iron concentration was determined from a calibration plot constructed beforehand. We then determined the Fe(III) content of the sample. For this, the required portion of the sulfosalicylic acid solution was added to an aliquot of the sample and the $\mathrm{pH}$ of the mixture was adjusted to 1 by adding a solution of hydrochloric acid (dilution, $3: 2$ ). After the mixture was left to react for $10 \mathrm{~min}$, its absorption at $510 \mathrm{~nm}$ was measured. The concentration of iron (III) was found from a calibration plot. The $\mathrm{Fe}$ (II) content of the sample was found by taking the difference between the total Fe and Fe(III) in the sample.

Spectrophotometric measurements were performed using a modified Specord M40 instrument interfaced to a computer; quartz cuvettes with light path of 1 to $10 \mathrm{~mm}$ were used.

Electrodeposition was carried out onto copper substrates in the galvanostatic mode (current density of $2 \mathrm{~A} / \mathrm{dm}^{2}$ ) in a $0.5 \mathrm{~L}$ cell with an anode made of type TM-3 graphite. Surface areas for electrodeposition were 0.05 and $2.5 \mathrm{~cm}^{2}$. Considering that galvanostatic electrodeposition was done onto samples with the different surface areas, the volume current density (VCD) in these experiments was different, viz., 2 and $200 \mathrm{~mA} / \mathrm{L}$. Earlier studies [32-34] established that electrodeposition of alloys between the iron group metals and tungsten was accompanied by a size effect 
in the surface properties (microhardness), i.e., microhardness of coatings electroplated at a fixed current density varied with the VCD. Prior to each experiment, copper substrates were plated with a layer of nickel in a bath containing $\mathrm{NiCl}_{2} \cdot 6 \mathrm{H}_{2} \mathrm{O}(240 \mathrm{~g} / \mathrm{L})$ and $\mathrm{HCl}$ (conc.; $80 \mathrm{~g} / \mathrm{L}$ ) at a current density of $3 \mathrm{~A} / \mathrm{dm}^{2}$, which, over $60 \mathrm{~s}$ of deposition duration, produced nickel layers with a thickness of $\sim 0.5 \mu \mathrm{m}$.

The surface morphology of prepared samples was examined using a HitachiTM 360 scanning electron microscope (SEM). The instrument was equipped with an attachment for energy-dispersive X-ray spectroscopy (EDS) which we used for elemental analysis. Microhardness was measured using a PMT-3 microhardness tester. Indentations were made with a Vickers indenter at an indenter load of $100 \mathrm{~g}$. Surface roughness of electroplated coatings was measured on Surtronic surface roughness tester (Taylor Hobson). Each sample was measured at least three different points. The results of the measurements are presented as means with standard deviations.

A Hull cell with a rotating cylinder electrode (RCE), $12 \mathrm{~mm}$ in diameter and $30 \mathrm{~mm}$ in height, was used for determining the deposition rates and the properties of coatings; the variant used here was described in our earlier works [35, 36]. Electrodeposition was performed from either a quiescent bath or the electrode was rotated at $270-570 \mathrm{rpm}$. For the latter case, the Reynolds number was in the range of $10^{3}-2 \times 10^{3}$, which corresponds to a turbulent flow regime. In terms of component diffusion, the surface of RCE was therefore uniformly available in the longitudinal direction, i.e., the thickness of concentration gradient layer was uniform along the electrode length.

\section{RESULTS AND DISCUSSION}

\section{Forms of Iron in Citrate-Containing Solutions at Different $p H$}

The preparation of bath IV started by first preparing bath II, i.e., a solution of iron(II) sulfate in a citrate mixture. All experiments described below were conducted in an oxygen-free atmosphere. For this solutions were prepared using boiled distilled water and were purged with argon. A thus-prepared solution of iron(II) sulfate was found to contain less than $3 \%$ trivalent iron. However, the analysis showed 19\% trivalent iron, after the required amount of citrate mixture was introduced into the solution (which was accompanied by an increase in $\mathrm{pH}$ to 4). After the solution $\mathrm{pH}$ was adjusted to 5.5 , the trivalent iron content rose to $79 \%$, and at $\mathrm{pH}$ of 6.8 , the trivalent iron content was $92 \%$. This shows that if a salt of bivalent iron is used as a component of this type of plating bath, the bath actually contains the oxidized form of iron, with the extent of oxidation depending on the solution $\mathrm{pH}$ and the oxidizing agent being the citrate ion, not oxygen.

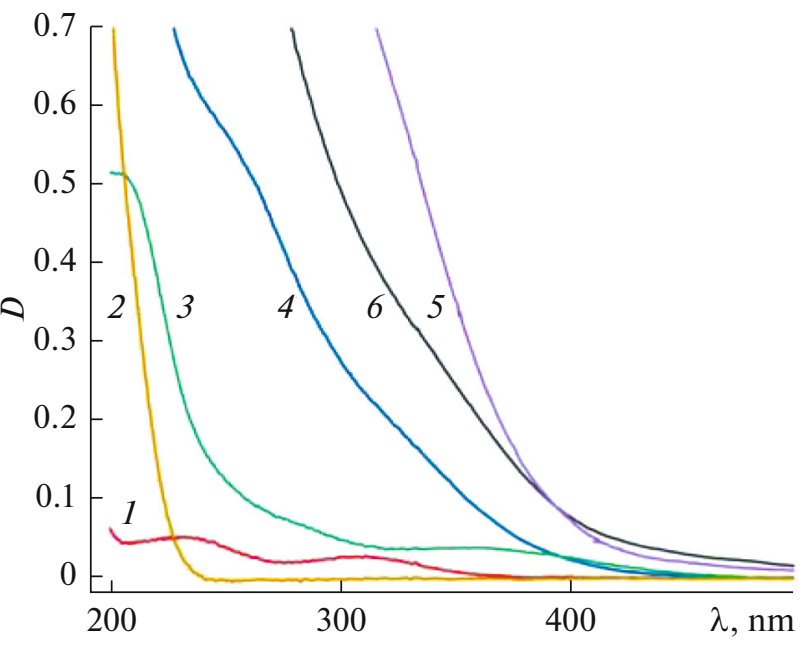

Fig. 1. UV absorption spectra of ( 1 ) an iron sulfate solution (strongly acidic medium), (2) the mixture of sodium citrate and citric acid ( $\mathrm{pH} 4.8)$, and $(3-6)$ bath II and different $\mathrm{pH}$ values: (3) 1, (4) 4.1, (5) 6.8, and (6) 8 .

UV absorption spectra for bath II at different $\mathrm{pH}$ are shown in Fig. 1, along with spectra of an aqueous solution of $\mathrm{Fe}$ (II) sulfate and a citrate solution. As can be seen, the spectrum of iron(II) sulfate feature two peaks, suggesting that possibly both bi- and trivalent iron species are present in the solution simultaneously. After the citrate was added, the absorbance grew, which may indicate that citrate complexes of both biand trivalent iron have formed. As the solution $\mathrm{pH}$ was raised from 1 to 8 , the color changed from pale yellow to intensely colored orange-greenish. Unfortunately, with these data alone, we cannot make any definitive statements about the type of complexes and the degree of oxidation of iron in them.

Additional information about the composition of complexes in the citrate solution can be obtained from CV (Figs. 2-5). The measurements were conducted in argon-purged solutions at $25^{\circ} \mathrm{C}$. We can see that the acidic solution $(\mathrm{pH} 1)$ contains hydrated iron ions (obviously, along with a citrate complex). The presence of the hydrated iron ions is indicated by a registered redox process that can be attributed to the $\mathrm{Fe}(\mathrm{III})_{\mathrm{aq}} / \mathrm{Fe}(\mathrm{II})_{\mathrm{aq}}$ redox couple. The standard potential for this system, $E_{0}=+0.55 \mathrm{~V}$ vs. $\mathrm{Ag} / \mathrm{AgCl}$ (sat.) [37], coincides with the half-wave potential of the redox process of interest ( $E_{1}$, inset in Fig. 2$)$. But it is clear that another complex (the oxidized form) was present in this solution. This complex undergoes irreversible reduction at a potential of $-0.25 \mathrm{~V}\left(E_{2}\right.$, inset in Fig. 2). The fact that hydrodynamic conditions (stirring of the solution) had no effect on this process indicates that this can be a process involving adsorbed species. This supposition was corroborated by that the rate of this process fell considerably on the backward segment of the CV (passivation of the surface was observed) (Fig. 2). 


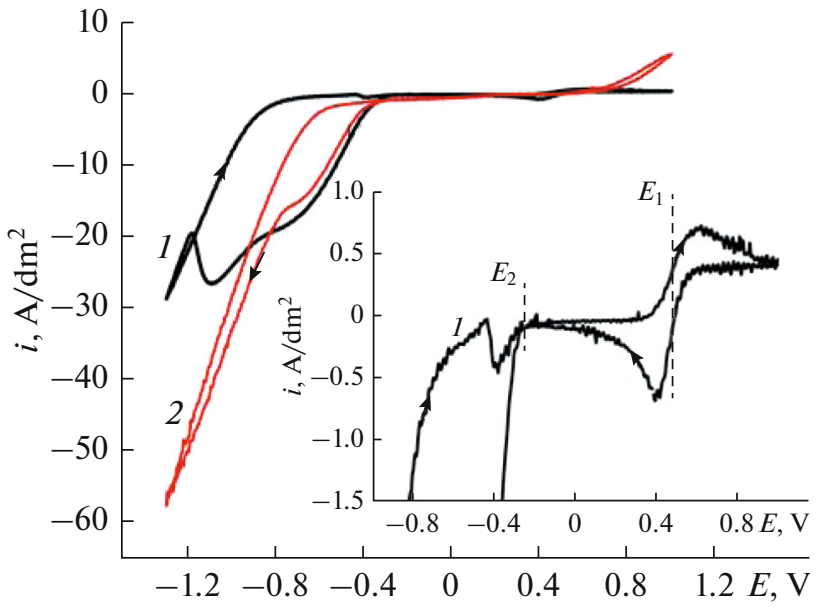

Fig. 2. CV curves recorded in bath II at $\mathrm{pH} 1$ (1) with and (2) without stirring.

Quite a different picture was seen at higher $\mathrm{pH}$ (Figs. 3-5). The current increased after the potential was reversed, and an anodic peak due to dissolution of the electrodeposited iron was observed in the anodic region (the potential $E_{3}$ measured at half of this peak is close to the standard potential of the $\mathrm{Fe} / \mathrm{Fe}$ (II) couple, which is $-0.66 \mathrm{~V}$ vs. $\mathrm{Ag} / \mathrm{AgCl}$ [37]). At the same time, this means that anodic dissolution of iron in a citrate solution yields bivalent iron species, and the overvoltage of this process is relatively low (in neutral solutions as well).

The data in Figs. 3-5 show that the CVs feature an irreversible redox process with a formal potential in the range of -0.25 to $-0.15 \mathrm{~V}$, its potential $E_{2}$ depending on $\mathrm{pH}$ and shifting anodically as $\mathrm{pH}$ increases. This process is likely to be oxidation-reduction of a citrate [38]:

$$
\mathrm{FeCit}+\mathrm{H}^{+}+\mathrm{e} \leftrightarrow \mathrm{FeHCit},
$$

where Cit is the triply-charged citrate anion.

In work [38], this process was considered irreversible (the peak potential depended on the potential scan rate). At $\mathrm{pH} \mathrm{4}$, the peak potential was $-0.25 \mathrm{~V}$ vs. $\mathrm{Ag} / \mathrm{AgCl}$ at slow scan rates [38]. These considerations strongly suggest that a reduction process observed at potentials more negative than the one indicated above can be identified as that described by reaction (1). This is a diffusion-controlled process. For this process, the limiting current density in a stirred solution at room temperature was $\sim 1.0 \mathrm{~A} / \mathrm{dm}^{2}$. Clearly, electrodeposition will not occur at applied current densities below this value, and the current efficiency at higher applied current densities will be reduced due to consumption of part of the charge by process (1).

The data shown in Figs. 3-5 indicate us the rate of oxidation of the citrate complex, which is also under diffusion control, increases with increasing $\mathrm{pH}$, which is in line with our previously described measurements

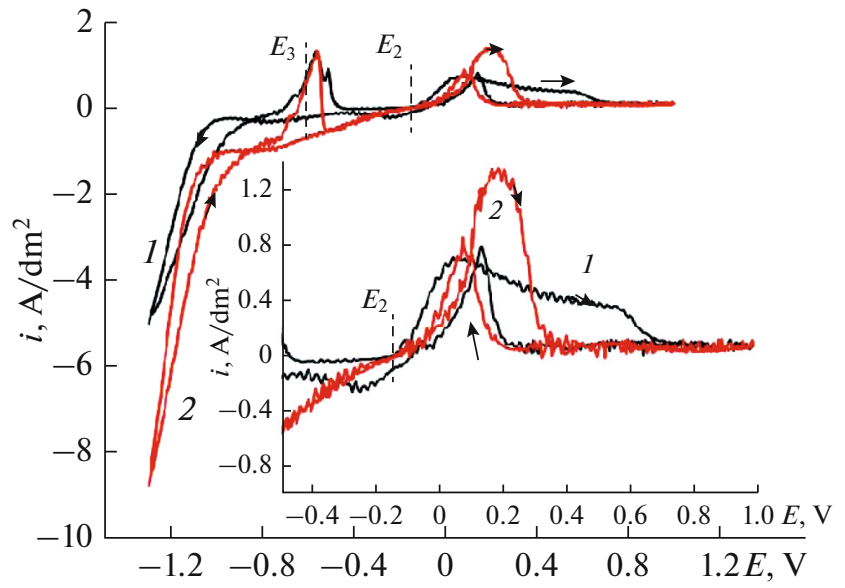

Fig. 3. CV curves recorded in bath II at pH 4.1 (1) with and (2) without stirring.

of the concentration of oxidized form of iron at different $\mathrm{pH}$. At the same time, the irreversibility of reaction (1) that follows from relatively low oxidation and reduction rates suggests that the concentration of oxidized form varies with time, a conclusion confirmed, in particular, by the results of study [39].

\section{Cyclic Voltammetry in the Bath for Electroplating $\mathrm{Fe}-W$ Coatings and in Partial Baths}

We can point to two significant differences between the results described in this section and those of the forgoing section. First, the experiments reported in this section were conducted at $80^{\circ} \mathrm{C}$, and second the $\mathrm{CV}$ measurements were done under otherwise ambient conditions, i.e., we did not remove the dissolved oxygen from solutions. Put differently, the experi-

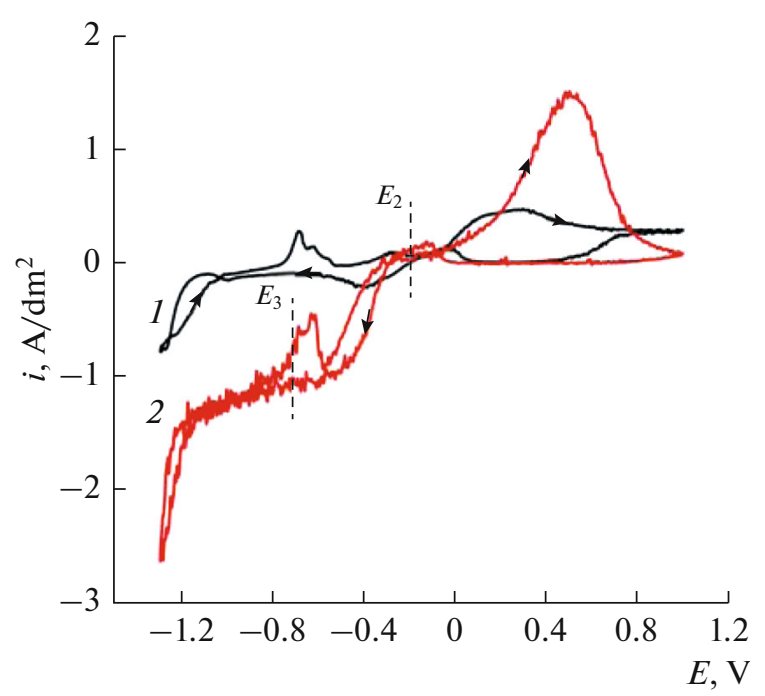

Fig. 4. CV curves recorded in bath II at pH 6.8 (1) without and (2) with stirring. 


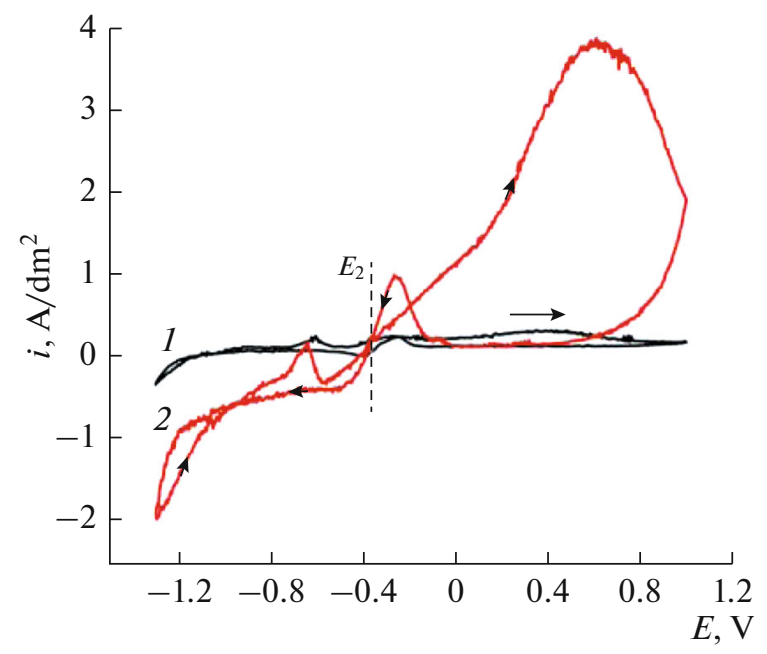

Fig. 5. CV curves recorded in bath II at pH 8 (1) without and (2) with stirring.

ments reported in this section closely imitated the processes that occur during actual electroplating of $\mathrm{Fe}-\mathrm{W}$ layers.

In the citrate solution (bath I), we observed a reduction process that was preceded with a peak at $-0.6 \mathrm{~V}\left(E_{4}\right.$, Fig. 6a). We cannot eliminate the possibility that this is an adsorption peak, since reduction at more negative potentials (higher current densities) results in surface passivation (the rate of the process diminished after reversal of potential scan), as can be seen from Fig. $6 a$.

In contrast, with iron species present in the solution, cathodic excursion of potential to $-1.3 \mathrm{~V}$ was accompanied by the deposition of a new phase (electrolytic iron), hence in the anodic region we registered peaks associated with its dissolution, and in the citrate solution the corresponding peak appeared at a potential $\sim 0.4 \mathrm{~V}$ more negative than in the sulfate solution with $\mathrm{pH} \sim 1$ (Fig. 6b). This difference was expected, considering that the difference in standard potentials between the $\mathrm{Fe} / \mathrm{Fe}(\mathrm{II})_{\mathrm{aq}}$ and $\mathrm{Fe} / \mathrm{Fe}(\mathrm{III})_{\mathrm{aq}}$ is $0.4 \mathrm{~V}$ [37]. Evidence that metallic iron dissolves in acidic sulfate solution to yield the oxidized form comes from the data shown in Fig. 6b. We can see that the backward segment of $\mathrm{CV}$ curve, in the region following the anodic dissolution of the iron at potentials of -0.2 to $+0.3 \mathrm{~V}$, features a cathodic limiting current due to reduction of the product formed as a result of the anodic dissolution, i.e., the reduction of the oxidized form. In contrast, oxidation of the reduced form of iron that formed as a result of iron dissolution in the citrate solution occurred at the same potentials (exceeding $-0.25 \mathrm{~V}$, i.e. $E_{2}$ ). Put differently, anodic dissolution of iron in an acidic sulfate solution yields $\mathrm{Fe}(\mathrm{III})$ species, while dissolution in a neutral citrate solution produces $\mathrm{Fe}$ (II) species in the solution. This conclusion is corroborated by the thermodynamic data (the foregoing analysis based on standard potentials) and the kinetic data on anodic dissolution of iron in so-called passivating electrolytes, inclusive of sulfate-containing ones [40-42].

By comparing the CVs recorded in baths II and IV (Fig. 7a), we can conclude that the anodic dissolution of electroplated $\mathrm{Fe}-\mathrm{W}$ coatings also occurs at potentials more positive, by $\sim 0.4 \mathrm{~V}$, than dissolution of electrolytic iron. The formation of an alloy and not crystalline iron is underpinned not only by the positive shift of anodic dissolution potential but the presence of a reduction wave at around $-1.0 \mathrm{~V}$ ( $E_{5}$ in Fig. 7a), which can be identified as the deposition potential of the $\mathrm{Fe}-\mathrm{W}$ alloy. The cathodic current density for this process is $\sim 2-5 \mathrm{~A} / \mathrm{dm}^{2}$. Clearly, electrodeposition of the alloy in the galvanostatic mode occurs in this range of applied current densities. At low applied current
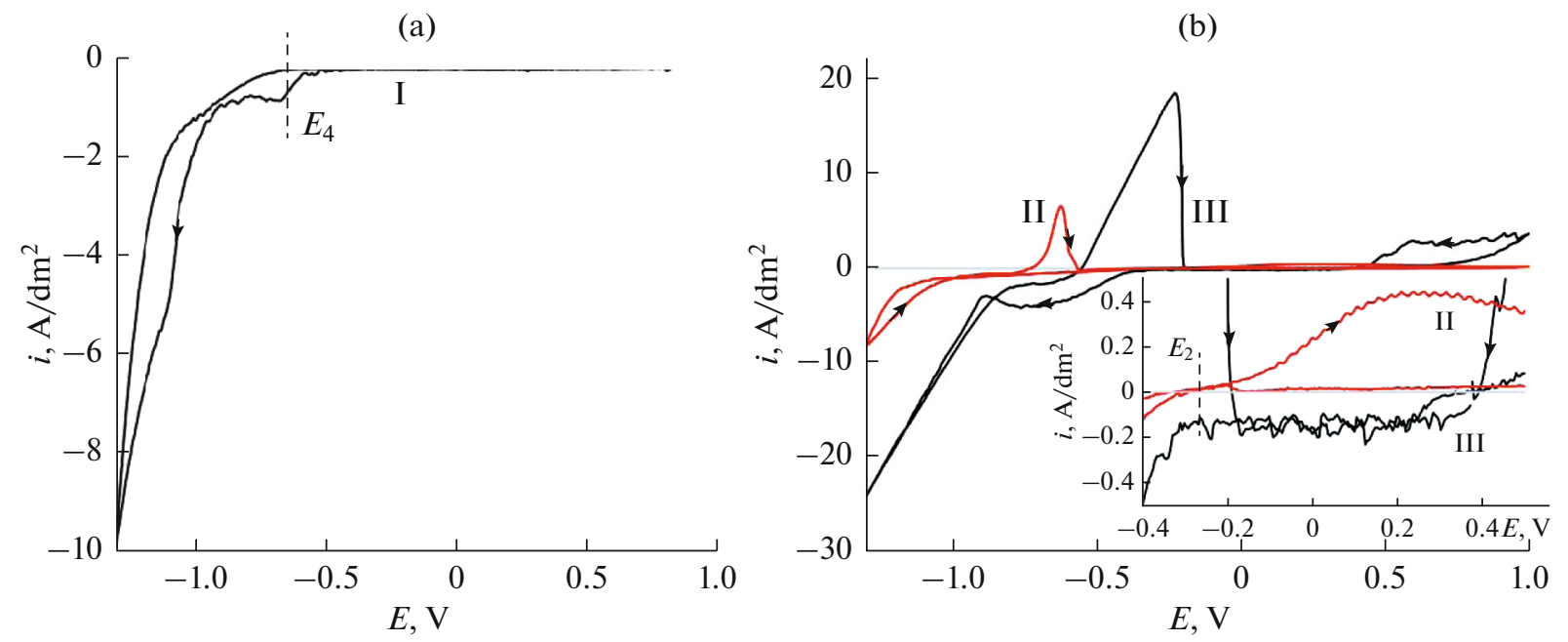

Fig. 6. CV curves recorded in (a) bath I and (b) baths II and III. 
(a)

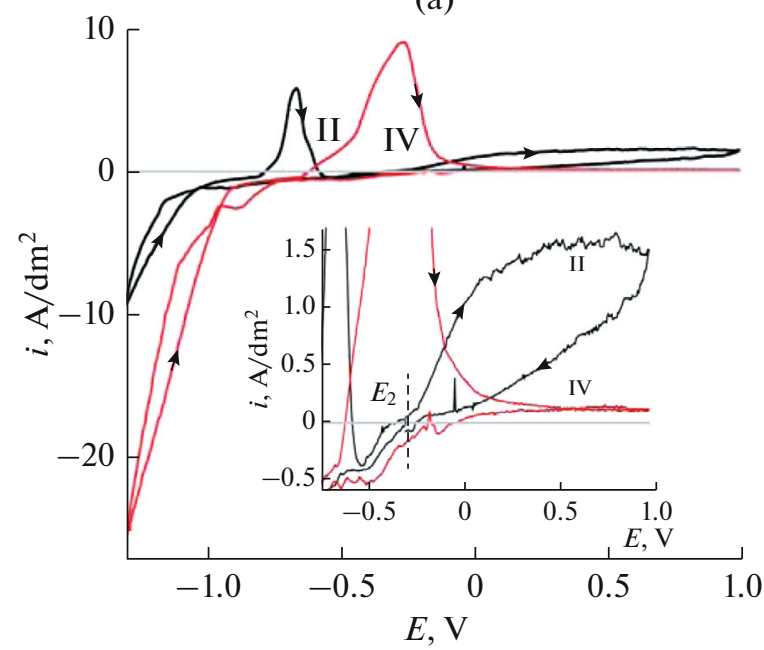

(b)

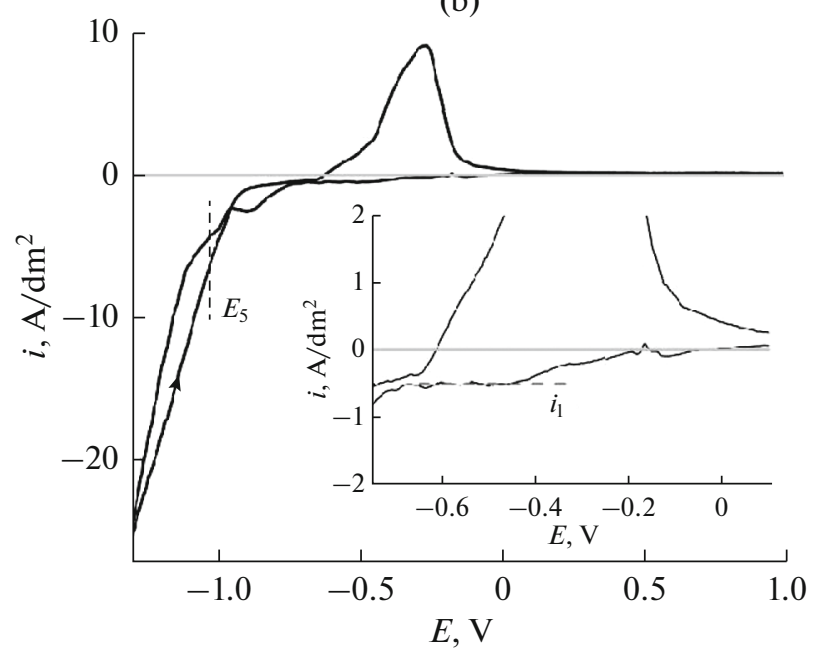

Fig. 7. CV curves recorded in (a) baths II and IV and (b) in bath IV for determining the limiting current due to reduction of the citrate complex.

densities, reaction (1), a side reaction in view of alloy plating, takes place, and at higher current densities we can anticipate the deposition rate falling due to hydrogen evolution reaction, which will result in lower current efficiency as well.

The value for liming current due to reduction of the trivalent iron (reaction (1)) can be estimated from the inset in Fig. 7b. As can be seen, the limiting current for this process (more precisely, a diffusion-limited current, as we discussed above) is $\sim 0.7 \mathrm{~A} / \mathrm{dm}^{2}$ in the range of potentials from -0.4 to $-0.7 \mathrm{~V}$. Apparently, this value can be considered as the maximum current density for the alloy electrodeposition. At lower densities of applied current, the current efficiency of alloy electrodeposition will drop to zero. Additionally, the results of the foregoing section suggest that this limiting current density will increase with the stirring rate, as well as the concentration of the oxidized form of the citrate complex, since this is a diffusion-limited current

In summary, applied current densities of $2-5 \mathrm{~A} / \mathrm{dm}^{2}$ can be considered as the operational current densities for electroplating of $\mathrm{Fe}-\mathrm{W}$ coatings from the quiescent citrate bath at $80^{\circ} \mathrm{C}$. Clearly, the stirring of solution must raise not only the limiting current of citrate reduction, but the operational current density of alloy electroplating as well.

\section{Composition and Properties of the Electroplated Alloys}

The results discussed below are for galvanostatic electrodeposition from bath IV at an applied current density of $2 \mathrm{~A} / \mathrm{dm}^{2}$ at $80^{\circ} \mathrm{C}$; the process was carried out in a $0.5 \mathrm{~L}$ cell equipped with a graphite anode. As was mentioned above (see also [31-33]), the surface properties (e.g., microhardness) can vary with the VCD. In other words, at a fixed current density and bath volume, the microhardness of an electroplated coating depends on the surface area of electrodeposition. In the experiments described here, electrodeposition was done at two different VCDs, 2 and $200 \mathrm{~mA} / \mathrm{L}$, which correspond to electrodeposition onto samples with surface areas of $2.3 \times 10^{-2}$ and $2.25 \mathrm{~cm}^{2}$, respectively. The surface morphology and an EDS spectrum for a sample prepared at the higher VCD are shown in Fig. 8. The surfaces of samples prepared at the same VCD are shown in Figs. $8 \mathrm{~b}$ and $8 \mathrm{c}$, but the sample shown in Fig. 8c was additionally polished with soft felt. Despite these surfaces appearing quite differently, their roughnesses were nearly identical $\left(R_{a}=0.23 \pm 0.07\right.$ and $0.29 \pm 0.09 \mu \mathrm{m}$, respectively). This seems to be an important remark, since the sample of Fig. 8c had a shiny surface, whereas that of Fig. $8 \mathrm{~b}$ had a matt appearance. The roughness was measured only on samples with the large area of electrodeposition, since measurements on small-area samples were hindered by the difficulty of fixating the samples.

EDS showed the presence of carbon and oxygen, along with $\mathrm{Fe}$ and $\mathrm{W}$, in the investigated sample. Therefore, the elemental composition of prepared samples was calculated in different ways. In the first variant, the composition was calculated considering only the metal components (the metal content was assigned $100 \%$ ), whereas in the second variant the oxygen content of the coating was taken into account as well. The results are listed in Table 2. In the table, the numbers before and after a slash refer to the second and first variant, respectively. We can see that the higher content of surface oxides is associated with the electrodeposition at the higher VCD.

According to a mechanism proposed in [17], an increase in the content of oxygen-containing impurities in such coatings may be related to chemical oxida- 


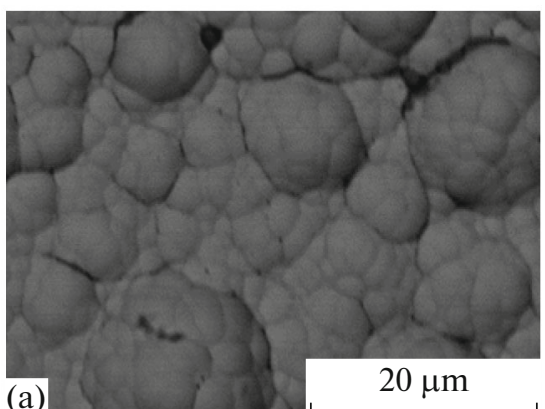

(a)

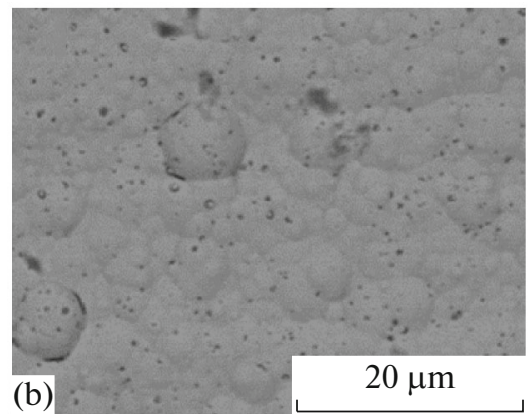

(d)

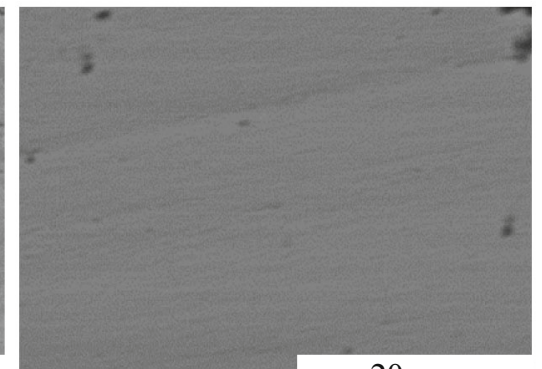

(c)

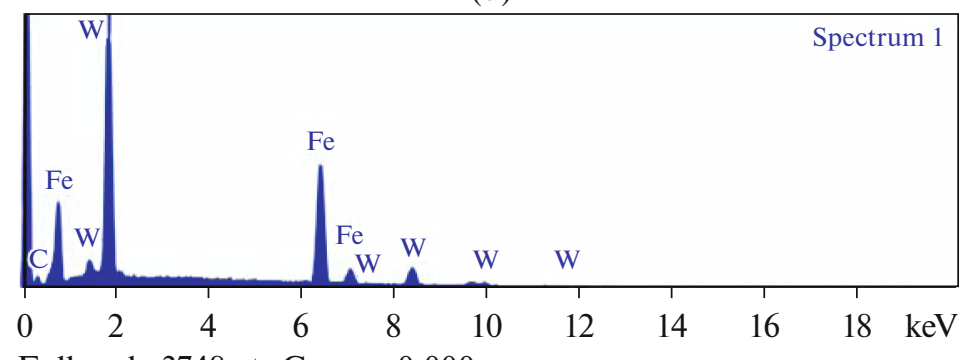

Full scale 3748 cts Cursor: 0.000

Fig. 8. Surface morphology of alloy samples prepared at a VCD of (a) $2 \mathrm{~mA} / \mathrm{L}$, (b) $200 \mathrm{~mA} / \mathrm{L}$, (c) $200 \mathrm{~mA} / \mathrm{L}$ followed by additional mechanical polishing of the surface. (d) EDS spectrum.

tion of an intermediate formed at the first stage of reduction of species inducing codeposition (in our case, iron). As a result, a composite with a high content of oxygen-containing impurities is formed in the coating, which ultimately leads to a reduction in microhardness. It can be that this caused the reduction in microhardness with increasing the VCD, which was observed in the experiment, since the oxygen content of the coatings grew, while the microhardness diminished, with increasing the VCD (Table 2).

The results of this section show that the tungsten content of coatings deposited from the plating bath under discussion constitute $\sim 25$ at $\%$, or, equivalently, $50 \mathrm{wt} \%$, which translates into a value of $1.09 \mathrm{~g} / \mathrm{A} \mathrm{h}$ for the electrochemical equivalent of the deposited alloy, taking into account that the alloy is produced from $\mathrm{Fe}(\mathrm{II})$ and $\mathrm{W}(\mathrm{VI})$ species.

\section{The Current Efficiency of Cathodic Deposition of Fe-W Coatings and Anodic Dissolution of Iron in the Citrate Bath}

The experimentally determined current efficiencies of the alloy electrodeposition at different applied current densities, with the calculated electrochemical equivalent of our alloy taken into account, are shown in Fig. 9. As can be seen, the current efficiency falls to zero at current densities below $0.7 \mathrm{~A} / \mathrm{dm}^{2}$, which is total agreement with the $\mathrm{CV}$ measurements. This is due to that the reduction of the iron(III) - citrate complex is the only electrochemical process at these current densities. The maximum current efficiency does not exceed $\sim 30 \%$, which can be explained by the contribution of reaction (1) in the overall process and the fact that the oxidized, and not reduced, form of iron undergoes reduction to give the alloy, a circumstance that substantially lowers the current efficiency.

Increasing the applied current density beyond $3-5 \mathrm{~A} / \mathrm{dm}^{2}$ also cause the current efficiency to drop due possibly to side reactions such as hydrogen evolution reaction or reduction of organic components of the bath (Fig. 9). Overall, the range of operational current densities for electrodeposition of $\mathrm{Fe}-\mathrm{W}$ coatings is markedly confined, from the side of both higher and lower potentials, by the reduction processes that are not accompanied by the formation of a solid phase, which should be taken into account in rational identification of the areas of applications for such coatings.

The CV measurements (Figs. 4 and 7) showed that iron anodically dissolves in the citrate bath to form iron species with the lowest degree of oxidation. This is corroborated by the data shown in Fig. 10 for an iron anode made of St20 steel. We can see that the current

Table 2. Elemental composition (at \%) and microhardness of electroplated coatings

\begin{tabular}{l|c|c}
\hline & $2 \mathrm{~mA} / \mathrm{L}$ & $200 \mathrm{~mA} / \mathrm{L}$ \\
\hline $\mathrm{Fe}$ & $62 \pm 2 / 77 \pm 2$ & $54 \pm 7 / 72 \pm 1$ \\
$\mathrm{~W}$ & $18 \pm 1 / 22 \pm 2$ & $23 \pm 2 / 28 \pm 1$ \\
$\mathrm{O}$ & $20 \pm 1$ & $28 \pm 5$ \\
$H V \mathrm{~kg} / \mathrm{mm}^{2}$ & $885 \pm 15$ & $724 \pm 18$ \\
\hline
\end{tabular}




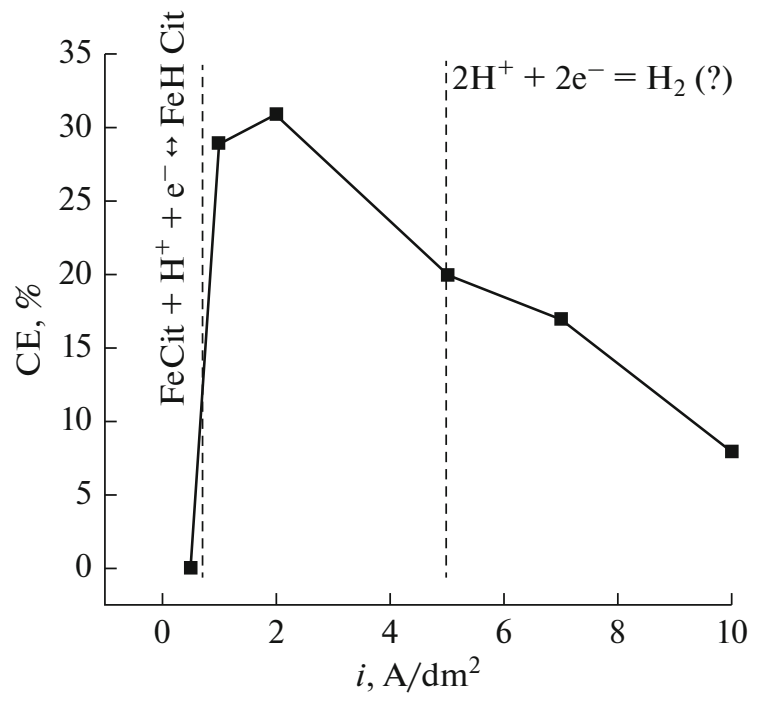

Fig. 9. Variation of the current efficiency of alloy electrodeposition with the applied current density.

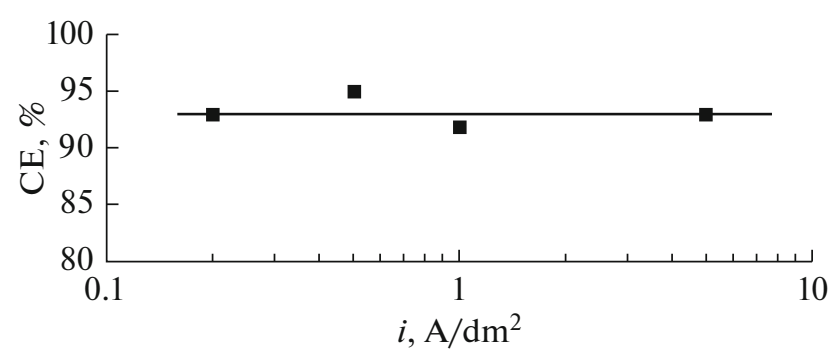

Fig. 10. Variation of the current efficiency of anodic iron dissolution in bath IV with the applied anodic current density.

efficiency, considering that anodic dissolution yields $\mathrm{Fe}$ (II) species in the solution, stays at $93 \pm 2 \%$ in a broad range of applied anodic current densities. At the same time, this result indicates to a possibility of using soluble iron anodes for electroplating of nanocrystal-

Table 3. Primary current distributions in the Hull cell with the RCE option

\begin{tabular}{c|l|l|c}
\hline \multirow{2}{*}{ Point no. } & \multirow{2}{*}{$x / H$} & \multicolumn{2}{|c}{$\begin{array}{c}\text { Mean current density, } \\
\text { A/dm }{ }^{2}\end{array}$} \\
\cline { 3 - 4 } & & 2 & 4 \\
\hline 1 & 0.1 & 6 & 12 \\
2 & 0.24 & 4 & 8 \\
3 & 0.37 & 2 & 4 \\
4 & 0.51 & 1.5 & 3 \\
5 & 0.64 & 1 & 2 \\
6 & 0.77 & 0.66 & 1.3 \\
7 & 0.91 & 0.5 & 1 \\
\hline
\end{tabular}

line $\mathrm{Fe}-\mathrm{W}$ coatings. Promising results for using a soluble tungsten anode in electroplating cobalt-tungsten coatings were obtained, in particular, in work [33]. An even greater effect can be anticipated from using a soluble iron anode in electroplating $\mathrm{Fe}-\mathrm{W}$ coatings, if we accept that the mechanism of induced codeposition follows the hypothesis put forward in [18, 19]. In this mechanism, the metal species inducing codeposition play a crucial role (in our case this is a citrate complex of bivalent iron), and therefore the technology for plating this alloy can be made much more efficient, if the concentration of this species is maintained at a constant level during the plating process.

\section{Distributions of the Electrodeposition Rate and Microhardness of Coatings, as Derived from Experiments Using a Hull Cell with a Rotating Cylinder Electrode}

The results reported in the foregoing sections, i.e., the deposition rate, coating composition, and microhardness, are for the experiments conducted at $80^{\circ} \mathrm{C}$, a typical temperature in our experiments, at one value of applied current density $\left(2 \mathrm{~A} / \mathrm{dm}^{2}\right)$, and in quiescent solutions. Using a Hull cell (with and without the RCE option $[34,35]$ ) enabled us to investigate the surface distribution of the deposition rate and the properties of coatings, as well as to evaluate the effects caused by hydrodynamic conditions. Listed in Table 3 are the values characterizing the primary current distribution for two mean applied current densities of electrodeposition, 2 and $4 \mathrm{~A} / \mathrm{dm}^{2}$. The height $H$ of the used RCE was $\sim 3 \mathrm{~cm}$. We note that the real distribution should be different from the one given in Table 3 . The presence of surface processes (overvoltage) causes the so-called secondary current distribution, which is a more uniform current distribution. Nonetheless, experimental determination of the thickness distribution for the deposited coatings enabled qualitative evaluation of the system behavior at different applied current densities.

The data on thickness distribution for the coatings deposited at $80^{\circ} \mathrm{C}$ (deposition time was $2 \mathrm{~h}$ in all experiments), as shown in Figs. 11, 12, and 14, suggest that the rate of electrodeposition from this bath always has a maximum at a certain point (in the longitudinal direction). Actually, that the current efficiency has a maximum at a particular applied current density (Fig. 9) implies that the deposition rate will also have a maximum at a certain point along the electrode length due to the nonuniform longitudinal distribution of current density, and this was observed experimentally. This, however, had no effect on the surface properties of deposited coatings (in this case, microhardness). The microhardness was nearly the same in a broad range of relative electrode lengths (we were not able to measure microhardness at high $x / H$ due to very small coating thicknesses). 
At the same time, the microhardness decreased appreciably after the mean applied current density was increased from 2 to $4 \mathrm{~A} / \mathrm{dm}^{2}$ (compare the data shown in Figs. 11 and 12). By comparing the values for microhardness to those of Table 2, we can see that all the microhardness data for both flat samples (Table 2) and the cylinder electrode collectively make up a single dependence of the microhardness on VCD (the VCD values for cylinder electrode experiments were 400 and $800 \mathrm{~mA} / \mathrm{L}$ for mean applied current densities of 2 and $4 \mathrm{~A} / \mathrm{dm}^{2}$, respectively). This dependence is plotted in Fig. 13. The values for microhardness of coatings obtained in the Hull cell that are included in the data of Fig. 13 are the average values for the microhardness data of Figs. 11 and 12. This therefore confirms the regularity identified in our previous studies [31-33]; namely, the VCD, and not applied current density, is a factor controlling the microhardness of such coatings (i.e., alloys between the iron group metals and tungsten).

Remarkably, stirring of the bath solution increased the electrodeposition rate at applied current densities confined to the operational range, but had no effect on the microhardness of our coatings (compare the data shown in Figs. 12 and 14); this being so, it has almost no effect on the thickness of coatings obtained at both low and high $i$.

The rate of electrodeposition of $\mathrm{Fe}-\mathrm{W}$ coatings from the citrate bath depends on hydrodynamic conditions in a complex manner (Fig. 15). The values shown in the figure were obtained at an applied current density of $2 \mathrm{~A} / \mathrm{dm}^{2}$ and are based on the measurements on the RCE surface at points corresponding to 0.37 of the total cylinder height. The data in Table 3 show that at this point the mean applied current density is equal to the local one. The complex dependency of the electrodeposition rate on the hydrodynamic conditions can be rationalized by that the latter affect both the current density of alloy electrodeposition, which increases the rate of electrodeposition, and the limiting current density due to reduction of the iron-citrate complex, which reduces the current efficiency of electrodeposition. At this current density, the maximum rate of electrodeposition $(15 \mu \mathrm{m} / \mathrm{h})$ is close to the one reported in work [24] $(17 \mu \mathrm{m} / \mathrm{h})$ for a citrate bath containing glycolic acid.

Localized deposition of a new phase, a characteristic feature of the process under discussion, can be favorably employed for spatially resolved, in particular, mask-free electrodeposition. That the current efficiency drops to zero as the applied current density is lowered can be a valuable feature for electrodeposition operated at small inter-electrode gaps, as it would ensure localization of the process in mask-free electrodeposition (see, e.g., [43]).

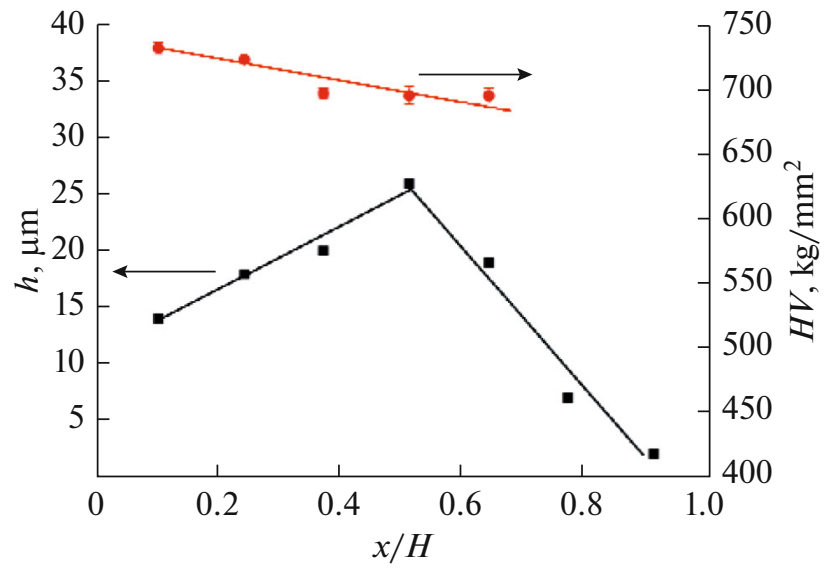

Fig. 11. Longitudinal distributions of thickness and microhardness for coatings deposited at a mean current density of $2 \mathrm{~A} / \mathrm{dm}^{2}$ from the quiescent bath.

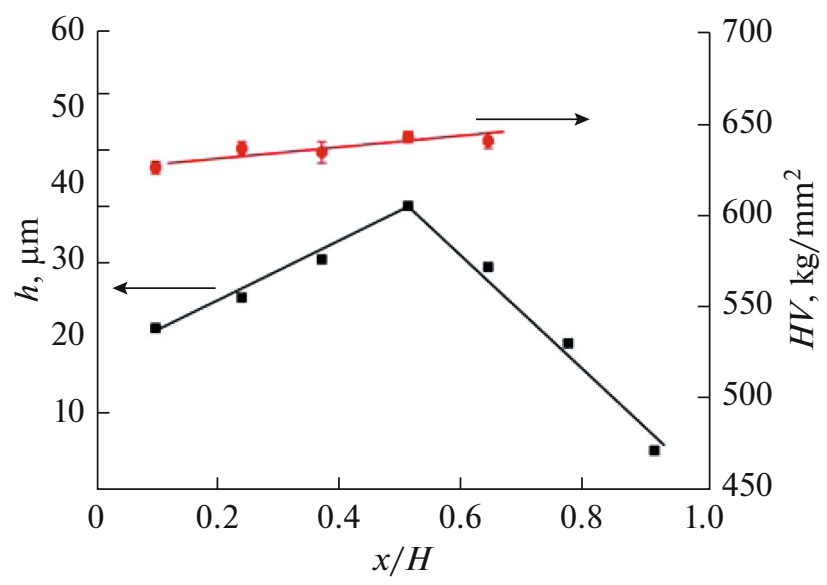

Fig. 12. Longitudinal distributions of thickness and microhardness for coatings deposited at a mean current density of $4 \mathrm{~A} / \mathrm{dm}^{2}$ from a quiescent bath.

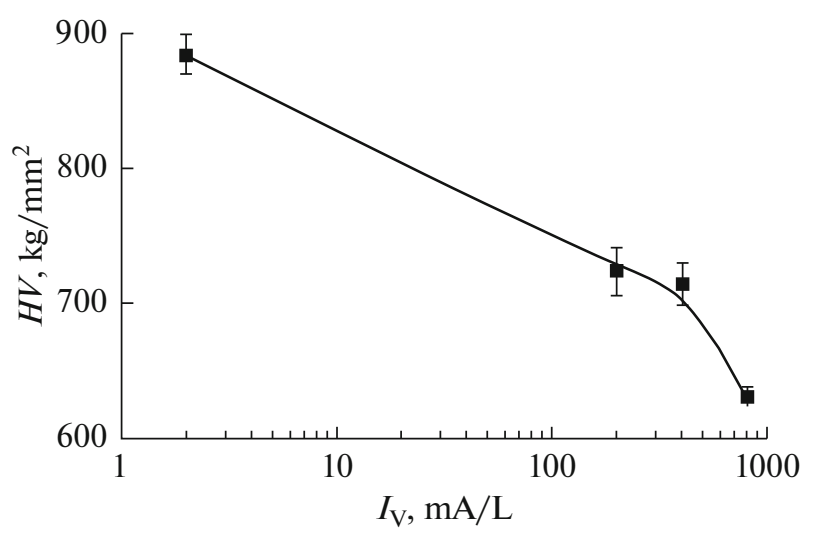

Fig. 13. Variation of coating microhardness with VCD. 


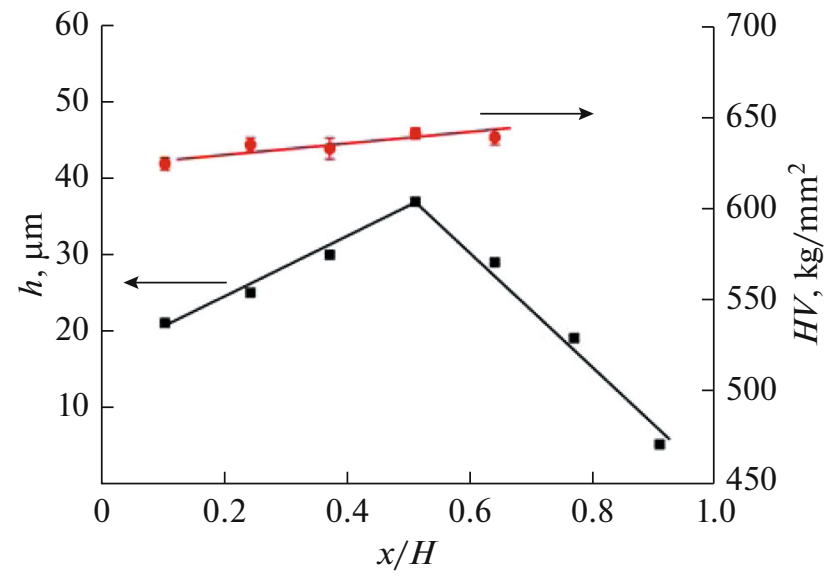

Fig. 14. Longitudinal distributions of thickness and microhardness for coating deposited onto the RCE (rotation rate, $410 \mathrm{rpm}$ ) at a mean current density of $4 \mathrm{~A} / \mathrm{dm}^{2}$.

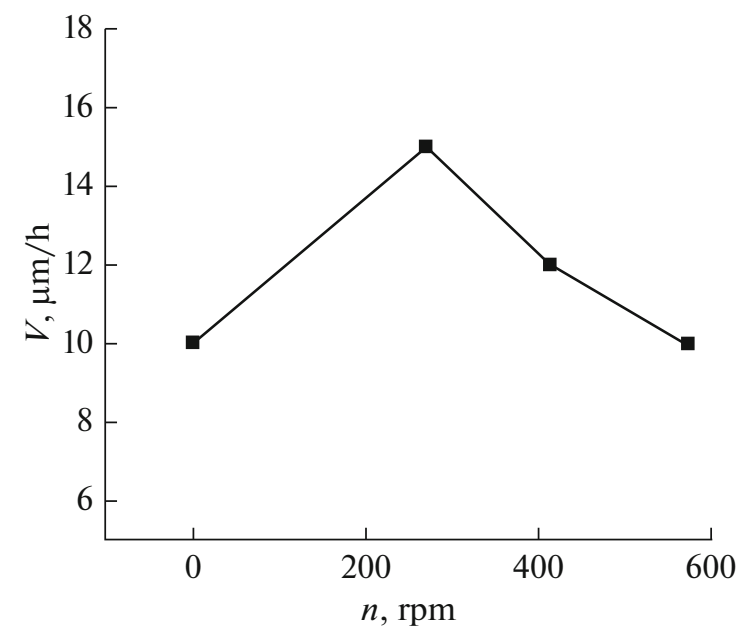

Fig. 15. Effect of the rotation rate of RCE on the electrodeposition rate of $\mathrm{Fe}-\mathrm{W}$ coatings at a current density of $2 \mathrm{~A} / \mathrm{dm}^{2}$.

\section{CONCLUSIONS}

We have used a combination of different methods-electrochemical (CV and the Hull cell with RCE option) and physical (SEM, EDS, and microhardness testing) - to investigate the baths for electroplating of nanocrystalline $\mathrm{Fe}-\mathrm{W}$ coatings and the properties of deposited coatings, and this led us to the following conclusions:

(1) oxidation of $\mathrm{Fe}(\mathrm{II})$ species in the citrate bath for plating the $\mathrm{Fe}-\mathrm{W}$ alloy that includes a salt of bivalent iron (viz., sulfate) occurs at the stage of bath preparation, with the rate of oxidation increasing with $\mathrm{pH}$ and the citrate ion being the likely oxidizing agent;

(2) since the formal potential for reduction of the formed iron-citrate complex is $-0.25 \mathrm{~V}$ (vs.
$\mathrm{Ag} / \mathrm{AgCl}$ ), the only electrode process occurring in a broad range of potentials, but before the electrodeposition potential of the alloy is reached $(\sim-1.0 \mathrm{~V}$ vs. $\mathrm{Ag} / \mathrm{AgCl}$ ), is the reduction of this citrate complex, which, being a side reaction, does not result in alloy electrodeposition;

(3) the rate of reduction of the citrate complex is limited by the diffusion-limited process, and so at applied current densities lesser than this one the current efficiency for the electrodeposition of $\mathrm{Fe}-\mathrm{W}$ alloy is zero;

(4) the operational applied current density of electrodeposition of $\mathrm{Fe}-\mathrm{W}$ alloys from the studied bath $(\mathrm{pH} \sim 6.9)$ lies in the range of $2-5 \mathrm{~A} / \mathrm{dm}^{2}$, and the current efficiency at higher applied current densities diminishes due to enhancement of side reactions such as hydrogen evolution and reduction of the organic components of the bath;

(5) the current efficiency for the anodic dissolution of iron in the citrate bath is $93 \pm 2 \%$, considering that $\mathrm{Fe}$ (II) species are produced in the solution, which enables us to recommend the use of soluble iron anodes in the technology of $\mathrm{Fe}-\mathrm{W}$ coatings;

(6) with the observed dependence of the current efficiency on the current density, the studied system seems to be promising for localized mask-free electrodeposition; and

(7) the rate of deposition and the microhardness of coatings can be controlled by controlling the hydrodynamic conditions and the VCD, respectively.

\section{ACKNOWLEDGMENTS}

This work was supported by the budget of the institutional project "Physicochemical Methods for Obtaining New Materials and Surfaces for Multiscale Technologies" (no. 15.817.02.05A), the project "H2020 Smartelectrodes" (no. 778357), and the Shevchenko Pridnestrovie State University.

\section{REFERENCES}

1. Eliaz, N. and Gileadi, E., Mod. Aspects Electrochem., 2008, vol. 42, pp. 491-520.

2. Tsyntsaru, N., Cesiulis, H., Donten, M., et al., Surf. Eng. Appl. Electrochem., 2012, vol. 48, no. 6, pp. 491520.

3. Brooman, E.W., Met. Finish., 2002, vol. 102, pp. 42-54.

4. Weston, D.P., Shipway, P.H., Harris, S.J., and Cheng, M.K., Wear, 2009, vol. 267, pp. 934-943.

5. Weston, D.P., Harris, S.J., Capel, H., et al., Trans. Inst. Met. Finish., 2010, vol. 88, no. 1, pp. 47-56.

6. Tsyntsaru, N., Dikusar, A.I., Cesiulis, H., et al., Powder Metall. Met. Ceram., 2009, vol. 48, pp. 419-428.

7. Wang, S., Zeng, C., Ling, Yu., et al., Surf. Coat. Technol., 2016, vol. 286, pp. 36-41.

8. Ved', M., Nenastina, T., Shtefan, V., et al., Mater. Sci., 2008, vol. 44, p. 840 . 
9. Yapontseva, Yu.S., Dikusar, A.I., and Kublanovskii, V.S., Surf. Eng. Appl. Electrochem., 2014, vol. 50, no. 4, pp. 330-336.

10. Cesiulis, H., Tsyntsaru, N., Podlaha, E.J., et al., Curr. Nanosci., 2018, vol. 14, pp. 1-16.

11. Khan, H.R. and Petrikovski, K., J. Magn. Magn. Mater., 2002, vol. 249, no. 3, pp. 458-461.

12. Tsyntsaru, N., Silkin, S.A., Cesiulis, H., et al., Electrochim. Acta, 2016, vol. 188, no. 10, pp. 589-601.

13. Tsyntsaru, N., Cesiulis, H., Peliser, E., et al., Electrochim. Acta, 2013, vol. 104, pp. 94-103.

14. Nicolenko, N., Tsyntsaru, N., Fornell, J., et al., Mater. Des., 2018, vol. 139, pp. 428-438.

15. Podlaha, E.J. and Landolt, D., J. Electrochem. Soc., 1996, vol. 143, pp. 885-893.

16. Podlaha, E.J. and Landolt, D., J. Electrochem. Soc., 1996, vol. 143, pp. 893-899.

17. Krasikov, V.L., Byull. S.-Peterb. Gos. Tekhn. Univ., 2015, no. 31, pp. 40-43.

18. Krasikov, V.L. and Krasikov, A.V., Byull. S.-Peterb. Gos. Tekhn. Univ., 2016, no. 36, pp. 12-23.

19. Krasikov, A.V. and Krasikov, V.L., Byull. S.-Peterb. Gos. Tekhn. Univ., 2016, no. 37, pp. 8-14.

20. Brenner, A., Electrodeposition of Alloys, New York: Academic, 1963.

21. Holt, L. and Black, R., J. Electrochem. Soc., 1942, vol. 82, no. 1, p. 205.

22. Brenner, A., Burkhead, P.S., and Seegmiller, E., J. Res. Natl. Bur. Stand., 1947, vol. 39, pp. 351-383.

23. Gamburg, Yu., Zahkarov, E., and Gorynov, G., Russ. J. Electrochem., 2001, vol. 37, pp. 670-673.

24. Nicolenko, A., Tsyntsaru, N., and Cesiulis, H., J. Electrochem. Soc., 2017, vol. 164, no. 9, pp. D590-D596.

25. Mulone A., Nicolenko A., Hoffman V., et al., Electrochim. Acta, 2018, vol. 261, pp. 167-177.

26. Bobanova, Zh.I., Dikusar, A.I., Cesiulis, H., et al., Russ. J. Electrochem., 2009, vol. 45, pp. 895-901.

27. Thangaraj, N., Tamilarasan, K., and Sasikumar, D., Indian J. Pure Appl. Phys., 2014, vol. 52, p. 395.
28. Kuznetsov, V.V., Golyanin, K.E., and Pshenichkina, T.V., Russ. J. Electrochem., 2012, vol. 48, pp. 1107-1112.

29. Tsyntsaru, N., Bobanova Zh.I., and Kroitoru D., Surf. Eng. Appl. Electrochem., 2010, vol. 46, pp. 538-546.

30. Yar-Mukhamedova, G., Ved', M., Sakhnenko, N., et al., Appl. Surf. Sci., 2016, vol. 383, pp. 346-352.

31. Charlot, G., Les Méthodes de la Chimie Analytique: Analyse Quantitative Minérale, Paris: Masson et Cie, 1960.

32. Silkin, S.A., Gotelyak, A.V., Tsyntsaru, N., and Dikusar, A.I., Surf. Eng. Appl. Electrochem., 2015, vol. 51, no. 3, pp. 228-234.

33. Belevskii, S.S., Bobanova, Zh.I., Buravets, V., et al., Russ. J. Appl. Chem., 2016, vol. 89, no. 9, pp. 14271433.

34. Gotelyak, A.V., Silkin, S.A., Yahova, E.A., and Dikusar, A.I., Russ. J. Appl. Chem., 2017, vol. 90, no. 4, pp. 541-546.

35. Madore, C., West, A.C., Matlosh, M., and Landolt, D., Electrochim. Acta, 1992, vol. 37, no. 1, p. 69.

36. Silkin, S.A., Belevskii, S.S., Gradinar, A., et al., Surf. Eng. Appl. Electrochem., 2010, vol. 46, no. 3, pp. 206214.

37. Spravochnik po elektrokhimii (Handbook on Electrochemistry), Sukhotin, A.M., Ed., Moscow: Khimiya, 1981.

38. Cox, J. and Cummings, E., J. Electroanal. Chem., 1973, vol. 42, pp. 153-157.

39. Francis, A.J. and Dodge, C.J., Appl. Environ. Microbiol., 1993, vol. 59, no. 1, pp. 109-113.

40. Mao, K.-W., J. Electrochem. Soc., 1971, vol. 118, no. 11, pp. $1876-1879$.

41. Chin, D.-T. and Wallace, A.J., J. Electrochem. Soc., 1973, vol. 120, no. 11, pp. 1487-1493.

42. Datta, M. and Landolt, D., Electrochim. Acta, 1980, vol. 25, no. 11, pp. 1263-1271.

43. Volgin, V.M., Kabanova, T.B., and Davydov, A.D., Chem. Eng. Sci., 2018, vol. 183, pp. 123-125.

Translated by A. Kukharuk 